NBSIR 78-1430

\title{
An Instrument to Evaluate Installed Smoke Detectors
}

Thomas G. K. Lee

Center for Fire Research Institute for Applied Technology National Bureau of Standards

Washington, D.C. 20234

February 1978

Final Report

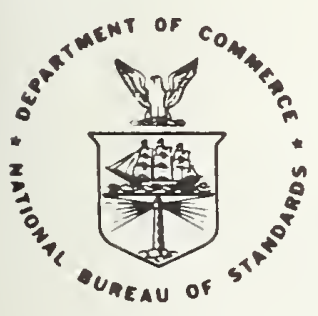

U.S. DEPARTMENT OF COMMERCE NATIONAL BUREAU OF STANDARDS 
NBSIR 78-1430

\section{AN INSTRUMENT TO EVALUATE INSTALLED SMOKE DETECTORS}

Thomas G. K. Lee

Center for Fire Research Institute for Applied Technology National Bureau of Standards

Washington, D.C. 20234

February 1978

Final Report

U.S. DEPARTMENT OF COMMERCE, Juanita M. Kreps, Secretary

Dr. Sidney Harman, Under Secretary

Jordan J. Baruch. Assistant Secretary for Science and Technology

NATIONAL BUREAU OF STANDARDS, Ernest Ambler, Acting Director 


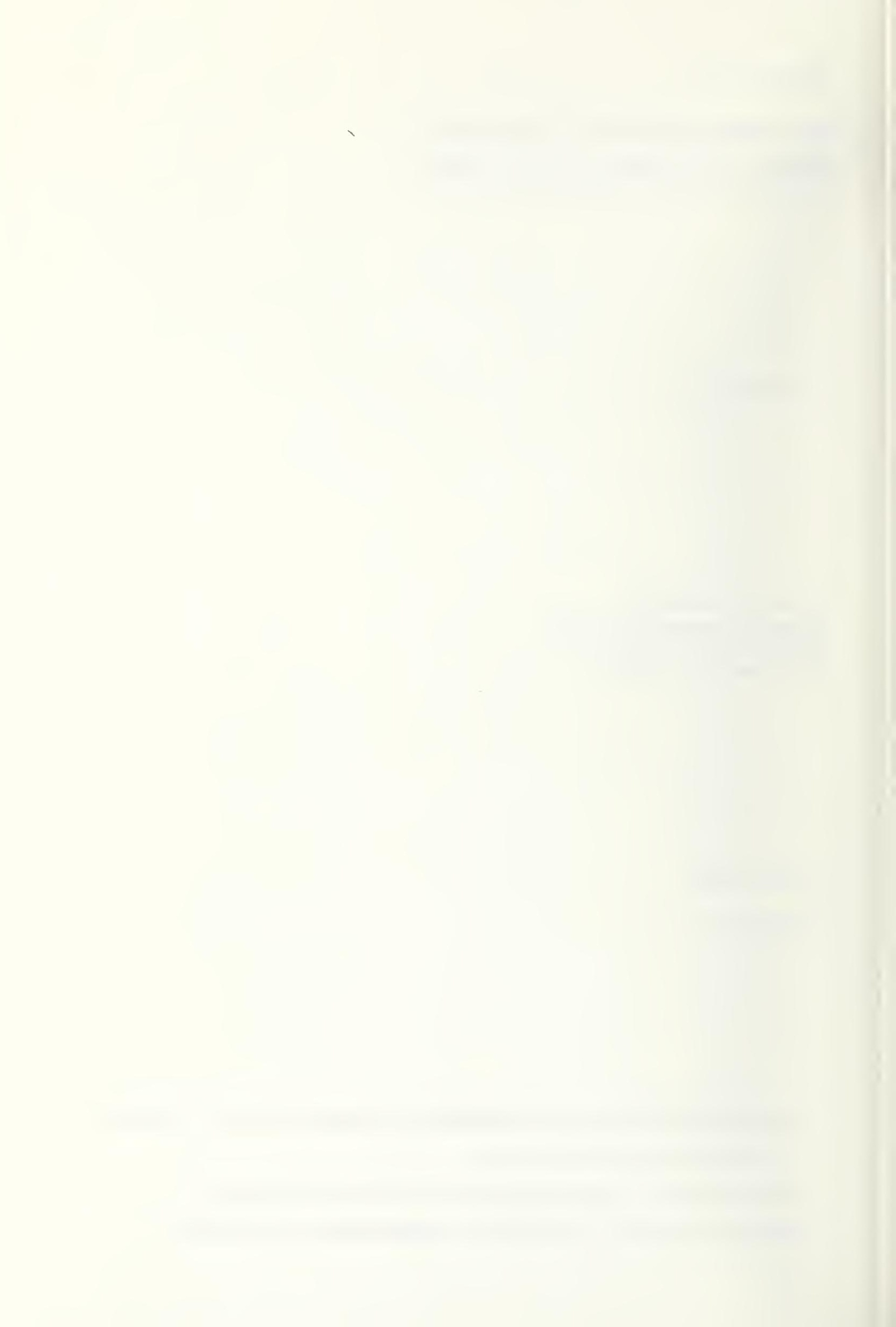


CONTENTS

Page

LIST OF FIGURES . . . . . . . . . . . . . . . . . . . IV

Abstract. . . . . . . . . . . . . . . . . . . . . 1

1. INTRODUCTION. . . . . . . . . . . . . . . . . 2

2. INTERACTION BETWEEN SMOKE AND DETECTORS . . . . . . . . . . 4

2.1 Fire Smoke and Its Characterization. . . . . . . . 4

2.2 Particle Size and Detector Response. . . . . . . . 5

2.3 Standard for Detector Sensitivity Evaluation . . . . . 6

3. THE DETECTOR TESTER . . . . . . . . . . . . . . . . 7

3.1 Control of Aerosol Concentration . . . . . . . . . 8

3.2 Dioctyl Phthalate (DOP), [Bis (2-ethylhexyl)phthalate], Kodaflax . . . . . . . . . . . . . 8

4. RESULTS AND DISCUSSION. . . . . . . . . . . . . . . . . 9 9

4.1 Effect of Temperature Pressure and Reservoir Height on Concentration . . . . . . . . . . . . . . . 9 9

4.2 Particle Size Distribution . . . . . . . . . . 10

4.3 Aerosol Optical Density, Number Concentration and Mass Concentration ... . . . . . . . . . . 12

4.4 Concentration Range of the Tester. . . . . . . . . 13

4.5 Alarm Threshold of Some Detectors. . . . . . . . . 14

5. SUMMARY AND CONCLUSION. . . . . . . . . . . . . . . 15

6. ACKNOWLEDGMENTS . . . . . . . . . . . . . . . . 16

APPENDIX A. CHARACTERISTICS OF THE COMPONENTS . . . . . . . . . 17

A.1 Compressor, Nebulizer and Impactor . . . . . . . . 17

A. 2 Blower, Plumbing and Shroud. . . . . . . . . . . 19

APPENDIX B. CHARACTERISTICS OF THE PARTICLE MASS MONITOR • . • . 21 REFERENCES . . . . . . . . . . . . . . . . . . 22 
Figure No.

Page

1 Sensitivity of two types of detectors exposed to monodisperse aerosols. . . . . . . . . 25

2 Schematic of the smoke detector tester. . . . . . 26

3 A smoke detector and the tester . . . . . . . . 27

4 Interior view of the tester . . . . . . . . 28

5 Impactor and dilution system. . . . . . . . . 29

6 Size distribution of test aerosol and lamp wick smoke as measured by EAA. . . . . . . . . 30

7 Relative number concentration of test aerosol at selected size ranges as measured by the particle optical counter . . . . . . . . . . . 31

8 Logarithmic probability plots of the cummulative mass distribution of the test aerosol . . . . . . 32

9 Optical density of test aerosol as a function of aerosol mass and number concentration . . . . . .

10 Mass concentration of test aerosol at various rotameter settings. . . . . . . . . . . 34 
AN INSTRUMENT TO EVALUATE INSTALLED SMOKE DETECTORS

Thomas G. K. Lee

Abstract

An inexpensive portable instrument has been constructed to test the sensitivity response of installed fire smoke detectors. The test stream consists of impactor-selected small particles from aerosol generated by a pneumatic nebulizer and dilution air. The flow rate of the test stream is $140 \mathrm{~L} / \mathrm{min}$ and its aerosol concentration can be varled from 10 to $60 \mathrm{mg} / \mathrm{m}^{3}$, sufficient to cover the sensitive ranges of the nine typical detectors tested. The aerosol mass median particle diameter is $0.46 \mu \mathrm{m}$ and the breadth of the size distribution in terms of geometric standard deviation, is 1.5. The size distribution of the polydisperse aerosol at the output is independent of the aerosol concentration in the range of interest and is comparable to some fire smokes. Aerosol light obscuration as measured by a standardized photometer is linear with respect to the aerosol mass concentration $\left(\mathrm{mg} / \mathrm{m}^{3}\right)$ and has a ratio $2.3 \mathrm{~m}^{2} / \mathrm{g}$ for this aerosol compared to $1.5 \mathrm{~m}^{2} / \mathrm{g}$ for cotton lampwick smoke in the UL 217 chamber.

Key words: Aerosol generators; detector sensitivity; detector testers; light obscuration; particle size distribution; polydisperse aerosol; smoke detector. 


\section{INTRODUCTION}

An effective approach in reducing fire hazard to life and property is the use of early-warning devices such as smoke detectors. Studies have shown that fatalities might be reduced by about $40 \%$ if detectors were installed in all houses [1] ${ }^{1}$. A more recent experimental study (1976) concluded that detectors would provide adequate life saving potential under most real residential fire conditions [2]. Because of low cost, advertising, and in some cases building code requirements, smoke detector sales reached an estimated 8 million units in the United States in 1977 [3] and is expected to continue at the same rate for the next few years.

The reliability and life expectancy of the installed detectors are not known, although component design requirements for detectors listed by the Underwriters' Laboratories (UL) include a theoretical expected life of 12-15 years at 50\% failure rate. The best estimate by the manufacturers of the useful life of current detectors is about ten years [4].

Very little field data based on valid sampling of detector failure rate is available. A recent (1976) inspection of 186 apartments with single 12 to 18-month old smoke detectors of one model by the Fire Marshall's Office of a large city showed that $18 \%$ were inoperative [5]. The tests were based on blowing cigarette smoke into the units. A majority of the failures was attributed to burned-out incandescent bulbs in the light-scattering-type units. The example may not be typical because some apartment occupants simply silenced the detector to stop the trouble signal instead of attempting to repair the detector which included with it two spare lamps and instructions for such replacement $[4,5]$. The occupants might have failed to receive or have ignored instructions on maintenance of these types of detectors. Certainly detectors based on

1 Numbers in brackets refer to the literature references listed at the end of this paper. 
different design characteristics such as that of ion-chamber, or the LED light source for the light-scattering type, are not expected to have such problems in such short periods of time. Nevertheless the detectors in the above example are listed by UL and the Factory Mutual Research Corporation (FM) and conform to their standards.

Clearly, there is a need for periodic sampling surveys of installed smoke detectors of various types and manufacturers to determine their failure rate and sensitivity shift under different environmental conditions. Such information would be useful to consumers and manufacturers as well as the public agencies (i.e. local fire departments). The field data not only would encourage design of more reliable detectors, but it would also help define the problem, if any, for the agencies responsible for public fire safety.

To perform detector reliability surveys or periodic maintenance tests in large installations with hundreds of installed detectors, a portable and inexpensive tester is needed. A tester of this type is not available today.

The testing instrument should produce an aerosol of known and reproducible particle size characteristics with adjustable concentrations at the proper ranges. Limits for both repeatability (for a single instrument) and reproducibility (among instruments of the same design) in terms of aerosol concentration and particle size should be known and acceptable.

This report describes the design, construction, and calibration of a prototype of such a detector tester. It also gives some preliminary results on the particle size distribution of the aerosol, the adjustable concentration range in terms of optical density and mass concentration as well as some repeatability data. Finally, the sensitivity responses of some common smoke detectors are also compared using the tester. Several prototype instruments of this design are being built for field trial to pinpoint any field use problems. 
Before describing the tester, a brief discussion of fire smokes and smoke detectors in general would be helpful in understanding the instrument.

\section{INTERACTION BETWEEN SMOKE AND DETECTORS}

\subsection{Fire Smoke and Its Characterization}

Part of the combustion products from a fire are generated in the form of an aerosol, commonly called smoke. It consists of solid particulates, or liquid condensates with or without a solid kernel, of various sizes. Smoke does not consist of only a single particle size but has a range of particle sizes with a peak concentration at a certain size. Particle sizes may range between 0.005 and 5 micrometers.

The number size-distribution (defined as the number of particles in the aerosol within a certain discrete diameter range) of various smokes have been found to fit at least qualitatively, a log-normal distribution. The count (geometric mean) median diameter $\bar{D}_{g}$ and the geometric standard deviation, $\sigma_{g}$ (the breadth of size distribution), may be derived from such a distribution [6]. These two parameters are commonly used to characterize the polydisperse aerosols. For example cigarette smoke collected by a smoking machine simulating a single inhalation by a smoker may have a $\bar{D}_{g}=0.29 \mu \mathrm{m}$ and $\sigma_{g}=1.4[7]$.

Neither $\bar{D}_{g}$ nor the concentration of an aerosol remain stable with time, especially at the high concentration level (>1 $\left.{ }^{6} 10^{6} \mathrm{~cm}^{-3}\right)$ required for detector alarm. The quantity $\bar{D}_{g}$ will increase with time because of particle growth due to coagulation during particle collision, while the number concentration decreases rapidly. (It takes many small particles to form a single large particle.) The mean diameter of punk (incense stick) smoke, for example, will increase by about $30 \%$ in five minutes while its concentration decreases from $1 \times 10^{7} \mathrm{~cm}^{-3}$ to $0.44 \times 10^{7} \mathrm{~cm}^{-3}$ (particles per cubic centimeter) during the same period. Coagulation rate is proportional to the square of concentration, thus coagulation losses become important only at high concentrations. 
For a given material, smokes generated under smoldering exposure conditions are generally larger in mean particle size compared to that generated under active flaming. Under smoldering conditions, aerosols are generated at a high rate and are convected away from the source rather slowly; both conditions favor particle coagulation and growth.

\subsection{Particle Size and Detector Response}

The sensitivity (defined as signal output per unit change of aerosol concentration) of present day smoke detectors depends strongly on the particle size of the aerosol. These detectors will respond to particles in the size range of 0.01 to $5 \mu \mathrm{m}$. However, the degree of sensitivity to particle sizes within this range differs considerably between the types of detectors and depends primarily on the physical principle on which the detector operates. For example, the response of the light-scattering-type detector is roughly proportional to the 6 th power of the particle diameter for particles with diameter to wavelength of light ratio smaller than a few tenths; whereas, for the ionizationtype detector, the response is approximately a linear function of particle diameter. The commercial light-scattering-type detectors are practically insensitive to particles less than $0.1 \mathrm{\mu m}$ compared to the ionization type which can respond to particles as small as $0.01 \mu \mathrm{m}$. The light-scattering types are also sensitive to the refractive index of the smoke.

Figure 1 illustrates the strong size-dependence of detector response. In this figure, the sensitivities of an ion-chamber and a light-scattering detector are plotted as a function of particle size for monodisperse dioctyl phthalate aerosols in the number concentration range of $10^{4}$ to $10^{6} \mathrm{~cm}^{-3}[8]$.

The difference in mean particle size between the flame-generated and smolder-generated smokes mentioned earlier, combined with the variation of particle size sensitivity of the two types of detectors shown in 
Figure 1, resulted in the common observation that ion-chamber detectors are more sensitive to smoke from flaming combustion and that lightscattering detectors are more sensitive to smoke from a smoldering source $[9,10]$.

In addition to particle size and particle concentration, the refractive index (scattering and absorption coefficients) are also important characteristics of an aerosol affecting a light-scattering detector. Detector output can be 2 to 5 times higher when exposed to white colored or highly scattering smoke compared to black sooty smoke of the same concentration and particle size.

\subsection{Standard for Detector Sensitivity Evaluation}

Because of the large variation in concentration, particle sizes and refractive indices of potential fire smokes, aerosols selected for detector evaluation standards must necessarily be arbitrary. For convenience, UL uses an aerosol generated from a smoldering cotton lamp wick for their detector sensitivity test in the UL 217 standard [11].

The sensitivity requirement of the standard applies to all types of smoke detectors. It requires that the detector under test must alarm when the aerosol concentration reaches a level corresponding to an optical density of $0.06 \mathrm{~m}^{-1}$ ( 4 percent/ft) for minimum sensitivity and $0.006 \mathrm{~m}^{-1}(0.4$ percent/ft) for maximum sensitivity as measured by a given photometer with a $1.5 \mathrm{~m}$-pathlength in the UL standard smoke chamber. The mass concentration of lamp wick smoke matching the $0.06 \mathrm{~m}^{-1}$ optical density is about $40 \mathrm{mg} / \mathrm{m}^{3}$. The number or mass concentration required to attain the same obscuration level depends strongly on the particle size and refractive index of the smoke. A more detalled discussions on the UL 217 standard may be found in [12]. 


\section{THE DETECTOR TESTER}

The purpose of the tester is to provide a polydisperse aerosol to evaluate the sensitivity of installed smoke detectors. Unlike instruments used for research which require high precision and accuracy, the tester design must also consider other important factors. These include component reliability, ruggedness, convenience as well as cost and safety to the operator.

Though precision is not of primary importance, sufficient test data from several testers plus sufficient field results should be evaluated to provide for an estimate of the precision. Such documentation would help the operator to judge the significance of any perceived shift in sensitivity of the detectors tested.

Figure 2 shows the schematic of the tester. The generator is based on a commercially available nebulizer, which generates a polydisperse aerosol with a relatively large mass median diameter. An impactor reduces the median diameter by selectively removing the large-diameter particles. The remaining aerosol is diluted by a large volume of room air at a constant rate from the blower.

A diaphragm pump which serves as a compressor as well as a vacuum source, provides the air pressure necessary for the operation of the nebulizer. Aerosol output and its particle size distribution from the nebulizer is kept constant by maintaining a constant pressure from the compressor. To vary the aerosol concentration of the test stream, part of the aerosol from the generator is diverted to the vacuum source through an adjustable valve. The diverted aerosol is filtered to prevent system contamination before being measured by the rotameter.

Figures 3 and 4 present the exterior and interior views, respectively, of the prototype tester. (Figure 4 does not include later improvements such as a much larger filter and impactor manifold.) Figure 5 is a drawing of the impactor and dilution system of the tester. Details on 
the design and component characteristics of the tester are given in appendix $\mathrm{A}$ of this report.

\subsection{Control of Aerosol Concentration}

The concentration of the test aerosol is regulated by the removal rate of the undiluted aerosol at the impactor manifold. The rate is controlled by the vacuum valve and monitored by the rotameter. To calculate the true (STP) flow rate, the line vacuum (pressure) at locations immediately upstream and downstream of the rotameter as well as the rotameter reading itself must be known. The upstream vacuum is particularly sensitive to the filter size and loading, which changes with time.

On a short term basis and assuming constant filter and vacuum pump characteristics, a rotameter reading alone can be used to indicate an apparent (uncorrected) flow rate. Tester calibration can be based on this apparent rate.

\subsection{Dioctyl Phthalate (DOP),} [Bis (2-ethylhexyl)phthalate], Kodaf $1 a x^{2}$

Technical grade DOP is used as a liquid in the nebulizer. The nebulizer will also work using other liquids ${ }^{3}$ though the size distribution of the resulting aerosol could be different. DOP was selected

2 Certain commercial equipment, instruments, or materials are identified in this paper in order to adequately specify the experimental procedure. In no case does such identification imply recommendation or endorsement by the National Bureau of Standards, nor does it imply that the material or equipment identified is necessarily the best available for the

3 purpose.

Such as peanut oil. 
because it is a very stable, colorless, olly liquid with low vapor pressure. It is used in large quantity in the plastics industry and its properties are well documented.

The air contaminant exposure limit for DOP aerosol under OSHA regulation (29-CFR 1910.1000) for an eight-hour time-weighted average concentration in work places is $5 \mathrm{mg} / \mathrm{m}^{3}$. In detector testing, aerosol concentrations, between 10 and $30 \mathrm{mg} / \mathrm{m}^{3}$ are normally used. Aerosol leaving the test shroud is quickly diluted by the room air. However, appropriate precaution should be taken by personnel who use the tester continuously and in confined spaces.

\section{RESULTS AND DISCUSSION}

\subsection{Effect of Temperature Pressure and Reservoir Height on Concentration}

Since the testers are to be used in the field where conditions may not be 1deal, some of the variables that may affect the generator output rate were examined.

\section{Temperature}

It is known that the viscosity of the fluid in the nebulizer has some effect on its aerosol characteristics. Tests show that a change of temperature by $10^{\circ} \mathrm{C}$ from 23 to $33^{\circ} \mathrm{C}$ in the DOP liquid result in an average of a $7 \%$ increase in mass concentration in the test stream, an increase from an average of 28.0 to $32.0 \mathrm{mg} / \mathrm{m}^{3}$. It is believed that the percentage increase would be similar for other concentrations.

\section{Pressure}

Though pressure to the nebulizer is standardized and regulated to $0.103 \mathrm{MN} / \mathrm{m}^{2}$ (15.0 psig), pressure variations due to poor meter calibration or operator control may introduce error. Limited data from 0.100 to 0.106 $\mathrm{MN} / \mathrm{m}^{2}$ (14.5 to $15.5 \mathrm{psig}$ ) indicated that the concentration increases with 
pressure at a rate of about $15 \%$ per each psi increase. Therefore precision in pressure control is important for good repeatability.

\section{Liquid Level}

The level of liquid in the reservoir of the nebulizer may also affect the generation rate and thus the final aerosol concentration. Data based on three sets of experiments show that concentration in the test stream increases as the liquid level in the reservoir increases. The level is defined and measured after all the liquid has been emulsified by 2 to 3 minutes of operation of the nebulizer and recirculated back to the reservoir. The increase in output concentration was on the order of 6-9\% when the reservoir content was increased from 2 to $8 \mathrm{~mL}$. To minimize this effect, reservoir loadings between 5 and $8 \mathrm{~mL}$ were used throughout this work.

\subsection{Particle Size Distribution}

The particle size distribution of the test aerosol was measured by three different commonly used methods. These are: (1) the electrical aerosol analyzer (EAA); (2) the optical particle counter, and (3) the cascade impactor. The first two instruments give particle diameters based on count numbers whereas the last one is based on size derived from its collected mass. The electrical aerosol analyzer is based on a mobility analysis of charged particles. The charge acquired by "diffusion" charging is a function of the particle size [13]. The optical particle counter counts each particle and measures its forward scattered light intensity, which is a function of particle size [14]. The cascade impactor classifies the aerosol into size fractions according to particle momentum, and each collected size fraction is weighed to determine the distribution [15]. 
The result based on the electrical aerosol analyzer (EAA) is shown in figure 6. In this figure, comparison is made between lamp wick smoke generated in the UL 217 standard test chamber and the DOP test aerosol at different concentrations. For the test aerosol, $\overline{\mathrm{D}}_{\mathrm{g}}=0.17 \mathrm{~mm}$ and $\sigma_{\mathrm{g}}=$ 1.7 compares to lamp wick smoke of $\bar{D}_{g}=0.12 \mu \mathrm{m}$ and $\sigma_{g}=1.6$. The drop in concentration as particle size increased was not as steep for the test aerosol as the lamp wick smoke.

The distribution data are presented in terms of $\Delta N / \Delta \log D_{p}$ versus $D_{p}$ in a $\log -\log$ plot, where $\mathrm{N}$ is a number of aerosol particles per cubic centimeter and $D_{p}$ is the particle size in micrometers. The quantity $\Delta N$ represents the number of aerosol particles in the particle diameter size range $\log D_{p}$ to $\log D_{p}+\Delta \log D_{p}$. The $\Delta$ presentation was used because data obtained from the measuring instruments were based on the average within each discrete range.

Several EAA measurements at different test stream concentration levels between 40 and $70 \mathrm{mg} / \mathrm{m}^{3}$ show that the size distribution is independent of concentration.

To measure aerosol particles larger than $0.5 \mu \mathrm{m}$ for which the EAA is not efficient, an optical particle counter was used. The measurements based on a light-scattering type optical counter coupled to a multichannel pulse height analyzer (PHA), are shown in figure 7. This figure shows the relative particle concentration at various size ranges for samples before and after going thru the impactor. The cut-off near the $0.5 \mu \mathrm{m}$ region is relatively sharp. The size range corresponding to each channel. was on the order of $0.02 \mu \mathrm{m}$. The counter is insensitive to sizes smaller than $0.5 \mu \mathrm{m}$. Since the two curves are not based on the same dilution ratio, only the relative magnitude of each curve is significant. 
The third technique for size distribution measurement is that based on the mass distribution of the aerosol. An Anderson (7 stage) cascade impactor ${ }^{4}$ model 1ACFM [16] with a sampling rate $28.3 \mathrm{~L} / \mathrm{min}$ was used for this purpose. Figure 8 shows the results plotted on log-probability paper which plots the cumulative mass distribution as percent less than the stated size as function of the particle diameter. The $50 \%$ point or the mass median diameter ( $M M D)$ was $0.46 \mu \mathrm{m}$ according to the plot with a calculated $\sigma_{g}=1.5$. Four determinations at various concentration levels gave results in $M M D$ to within $\pm 0.1 \mu m$ based on the Anderson instruments.

The calculated $\bar{D}_{g}$ based on $\ln \bar{D}_{g}=\ln (\mathbb{M D})-3\left(\ln \sigma_{g}\right)^{2}$ is $0.28 \mu \mathrm{m} .^{5}$ This is higher than the $\bar{D}_{g}=0.17 \mu \mathrm{m}$ based on the EAA measurements. The discrepancy may be due to differences in sensitivity ranges in the two instruments and questionable log-normal assumption of the test aerosol conditioned by the impactor.

The essential point here is not necessarily that good agreement between two methods of measurement exist, but rather that replicate measurements at several aerosol concentrations give consistent results based on a single method. Results indicate that this is the case for particle size distribution in the test stream.

\subsection{Aerosol Optical Density, Number Concentration and Mass Concentration}

Underwriters' Laboratory standard UL 217 for smoke detector approvals evaluations is based on optical density measurement. This is a simplified method to measure aerosol concentration. Light obscuration measurements as a function of mass concentration for the test aerosol at various concentrations were made by a standardized 1-m path length photometer which has an incandescent light source (color temperature $2425 \mathrm{~K}$ ) and a

\footnotetext{
4 Calibrated according to mass diameter

5 In refers to the natural logarithm.
} 
S-4 response phototube corrected with a photopic filter for CIE human eye response [17]. The photometer is housed in a long narrow chamber 6 for rapid stream flow-thru in order to minimize aerosol aging. At the standard flow rate of $140 \mathrm{~L} / \mathrm{min}$ at least 3 minutes were needed to completely change the aerosol concentration in the chamber. In addition to optical density measurements, samples were also monitored continuously from the end of the chamber by the EAA and the particle mass monitor. The sensitivity of the mass monitor is on the order of $0.01 \mathrm{mg} / \mathrm{m}^{3}$. Calibration by the weighted filter method using DOP snowed good collection efficiency at our range of interest. Appendix B describes the mass monitor in more detail. Figure 9 shows the optical density as a function of measured number concentration and mass concentration.

Because of the difference in particle size and refractive index, the optical density to mass concentration ratio for the generated aerosol $\left(2.3 \mathrm{~m}^{2} / \mathrm{g}\right)$ is about $50 \%$ higher than the lamp wick smoke $\left(1.5 \mathrm{~m}^{2} / \mathrm{g}\right)$ used in the UL 217 test [12]. As a result light-scattering type detectors will be somewhat more sensitive to these aerosols than ion-chamber detectors if both detectors have equal sensitivity to the lamp wick smoke. However, the difference becomes insignificant because there is a wide difference in sensitivity setting among detectors of both types.

\subsection{Concentration Range of the Tester}

Under the present design configuration, without any change in dilution air rate, the concentration range of the tester is between 10 and $60 \mathrm{mg} / \mathrm{m}^{3}$. Because of its limited capacity, the vacuum source was not sufficient to remove all the generated aerosol. As a result, the minimum concentration achieved by the system was only $10 \mathrm{mg} / \mathrm{m}^{3}$ instead

$\overline{6 \text { Cross-sectional }}$ area is $929 \mathrm{~cm}^{2}$ 
of zero. 7 It is very unlikely, however, for a detector to alarm at aerosol concentrations below $10 \mathrm{mg} / \mathrm{m}^{3}$. If needed, the concentration may be reduced by a factor of 2 (from 10 to $5 \mathrm{mg} / \mathrm{m}^{3}$ ) by a corresponding increase in the dilution airflow to $280 \mathrm{~L} / \mathrm{min}$. This requires only partial closing of the blower vent.

Figure 10 is a calibration curve showing the concentration of the test aerosol sampled at the shroud by the mass monitor as a function of rotameter reading. The data also shows the degree of scatter. The calculated standard deviation for a single test relative to the calibration curve at a given setting is $1.0 \mathrm{mg} / \mathrm{m}^{3}$ in the 10 to $40 \mathrm{mg} / \mathrm{m}^{3}$ range; and slightly higher in the 40 to $60 \mathrm{mg} / \mathrm{m}^{3}$ range. Repeatability for a single test is $2.8 \mathrm{mg} / \mathrm{m}^{2}$. Repeatability defined as the difference between the average of $n$ tests and that shown by the calibration curve in a given setting, expected in $95 \%$ of the time, is $1.92 \sqrt{2}(\sigma / \sqrt{n})$; where $\sigma$ is the standard deviation and $\mathrm{n} \doteq$ number of tests.

\subsection{Alarm Threshold of Some Detectors}

Table 1 presents alarm thresholds on nine typical smoke detectors of various types exposed to test aerosols of different concentrations at the shroud. Numbers in the table denote exposure time to cause alarm or fail to alarm. The detectors, including ion-chambers and light-scattering types, were mounted on a wall while the operator covered the detector with the tester shroud by holding the rigid plastic connection in a horizontal position.

Alarm threshold levels of detectors tested varied from about 10 to $30 \mathrm{mg} / \mathrm{m}^{3}$. If the detector failed to alarm after a 50 second exposure, additional time did not change the result. Depending on the design

7 A different vacuum pump was able to reduce the concentration to zero. 
entrance characteristics, the detectors generally responded in less than 25 seconds. Response time appears shorter if the aerosol concentration is much higher than the threshold value.

Detectors that responded to an aerosol concentration change at a rotameter increment of five (about $1.7 \mathrm{mg} / \mathrm{m}^{3}$ ) were definite and repeatable (3 tests per detector) except in detector $\mathrm{E}$ where there was overlapping within an increment. The $1.7 \mathrm{mg} / \mathrm{m}^{3}$ increment corresponds to a change ranging from 6 to $17 \%$ for an initial concentration of 30 to $10 \mathrm{mg} / \mathrm{m}^{3}$. Smaller incremental changes to obtain better resolution of the threshold has not been investigated.

\section{SUMMARY AND CONCLUSION}

A portable tester based on commercially available components for evaluating the sensitivity of installed smoke detectors was designed and a prototype was constructed. It is based on selectively retaining the small-size fraction of a DOP aerosol generated by the Rectec nebulizer using a unique impactor. The final aerosol has a mass median diameter of $0.46 \mu \mathrm{m}$, comparable to smoke in the UL 217 chamber. Particle size distribution was very stable.

The flow rate of the test stream is $140 \mathrm{~L} / \mathrm{min}$ and the concentration of the aerosol ranges between 10 and $60 \mathrm{mg} / \mathrm{m}^{3}$, sufficient to activate all the detectors tested. The concentration range can be extended or reduced by a factor of 2 if necessary.

Variables such as air pressure, liquid temperature and liquid leve1 contributed to the uncertainty. The greatest source of uncertainty is in the method adopted to vary the aerosol concentration. This relies on flow rate differences to determine the proportion of the aerosol removed from the output before dilution. Direct monitoring of the aerosol with a light-scattering or ion-chamber instrument could provide a direct 
measure of relative change in concentration and greatly improve the precision. However, the present precision is sufficient for most applications.

Laboratory tests for alarm threshold of nine typical smoke detectors using the developed tester showed good repeatable results to within $1.7 \mathrm{mg} / \mathrm{m}^{3}$. Testers based on this design should undergo field trial to determine problems encountered by field operators and to obtain data on the reproducibility among testers.

\section{ACKNOWLEDGMENTS}

The author wishes to thank Dr. George Mulholland for his many suggestions and assistance so that this study could be completed within the time constraint. 


\section{APPENDIX A. CHARACTERISTICS OF THE COMPONENTS}

\section{A.1 Compressor, Nebulizer and Impactor}

\section{Compressor}

The electric compressor selected to power the nebulizer utilizes a diaphragm pump. These reliable, low-noise units have been produced commercially for other applications for many years. It can deliver up to $12 \mathrm{~L} / \mathrm{min}$ with a working pressure of 20 psig.

To maintain a nebulizer pressure of 15 psig, the standard adopted for this design, excessive air from the compressor is vented thru an adjustable valve. Experience showed that the pressure stayed constant after initial adjustment. However, a small adjustment is needed when the vacuum setting is changed to vary the concentration of the test aerosol. An accurate ( \pm 0.1 psig) $15-\mathrm{cm}$ diameter Bourdon-tube gage monitors the pressure.

A pleated filter ( $2 \mu \mathrm{m}$ pore size) with a dead volume of about $200 \mathrm{~cm}^{3}$ not only cleans the compressed air but also dampens pressure oscillations from the pump.

Another outlet from the diaphragm pump is the vacuum source. It is utilized thru a valve to control the amount of aerosol being dumped so as to change the concentration of the test aerosol. A vent with an attached filter is also connected to the vacuum source to provide a minimum flow to avoid pump damage caused by excessive vacuum.

\section{Nebulizer}

The heart of the generator is the Retec nebulizer, which has been used for many years in inhalation therapy [18]. A nebulizer is an atomizer used to provide aerosols of fine particles by atomization of liquid to produce droplets, the majority of which are less than $10 \mathrm{~m}$ in diameter. In this particular design, high pressure air from a nozzle 
picks up a fluid (gas and liquid) and spreads it onto a close-coupled spherical target as a film. The liquid component becomes progressively thinner as it is forced at high velocity over an increasing surface. The liquid surface tension eventually overcomes and breaks the film into small particles. The principle and construction of various nebulizers have been reviewed by Raabe [19].

The sma11, a11 plastic Retec $\mathrm{X}-70 / \mathrm{N}$ unit has a liquid holding capacity of $10 \mathrm{~mL}$. At an operating pressure of $15 \mathrm{psig}$, the gas flow rate was about $4.7 \mathrm{~L} / \mathrm{min}$. The liquid output rate based on DOP (diocty1 phthalate) was $0.2 \mathrm{~mL} / \mathrm{min}$, thus allowing at least 20 minutes of operation between refills. The 22-mm OD outlet of the nebulizer is coupled to the impactor manifold by a rubber o-ring seal; the nebulizer may easily be removed for liquid refill.

Before reaching the impactor, the output number concentration of the aerosol from the nebulizer is on the order of $10^{7}$ particles per $\mathrm{cm}^{3}$, including large particles.

To determine the reproducibility of the flow rate, 12 different nebulizers were examined. A flow rate range of $4.7 \pm .25 \mathrm{~L} / \mathrm{min}$ was found. To minimize error introduced by such variability, only selected units with a tolerance of $4.7 \pm 0.05 \mathrm{~L} / \mathrm{min}$ were used in the construction of the generator. The plastic orifice that governs the flow rate may be purchased as a part at nominal cost from the manufacturer.

Possible deterioration of the nebulizer after long use, which may alter the aerosol characteristic, has not been investigated. However, a one-month immersion of the plastic orifice from a nebulizer in DOP showed no observable change in aerosol characteristic. 
Impactor

An impactor is used to control the upper particle-size limit of the aerosol from the nebulizer. Because of its large momentum, the largesize particles cannot follow the air stream in the sharp turns of the impactor. As a result these particles hit the vertical impaction plate, form a liquid film and drop away after sufficient accumulation.

By adjusting parameters such as the diameter and number of holes, the impactor can be designed to selectively change the upper size characteristic of the aerosol. The design parameters for inertia impactors have been reviewed by Marple [20]. The present design is based on those criteria for a sharp $50 \%$ cut-off point at $0.5 \mu \mathrm{m}$ for a $5 \mathrm{~L} / \mathrm{min}$ total flow rate with Reynolds number of 3000 thru each hole. The impactor consists of 5 holes with $0.53 \mathrm{~mm}$ ID drilled in a stainless steel disc $1.3 \mathrm{~mm}$ thick and $22 \mathrm{~mm}$ in diameter. The distance between the impaction plate and the hole plate is $0.78 \mathrm{~mm}$. The impactor changed the DOP aerosol MMD from $2.0 \mu \mathrm{m}$ to $0.46 \mu \mathrm{m}$.

Figure 5 is a drawing of the impactor and dilution system of the tester.

\section{A. 2 Blower, Plumbing and Shroud}

B1 ower

The squirrel cage blower rated at $1.7 \mathrm{~m}^{3} / \mathrm{min}$ free air and based on a 115 VAC shaded-pole motor, is a rugged inexpensive and commonly used exhaust blower. This normally high capacity blower is necessary to overcome the flow pressure drop of about $124 \mathrm{~N} / \mathrm{m}^{3}\left(0.5 \mathrm{~cm}\right.$ of $\left.\mathrm{H}_{2} \mathrm{O}\right)$ thru the $2.5 \mathrm{~m}$-length of hose connecting the generator and the shroud of the tester. The excessive blower capacity is vented back to the room thru a tee connection. The magnitude of venting maintains the constant rate of dilution air to the generator. 
Dilution airflow is monitored by an orifice meter with a thin $19 \mathrm{~mm}$ ID orifice plate. The differential pressure of the orifice is on the order of $200 \mathrm{~N} / \mathrm{m}^{2}\left(0.8 \mathrm{~cm} \mathrm{H}_{2} 0\right)$ for the standard flow rate of $140 \mathrm{~L} / \mathrm{min}$ in a $27 \mathrm{~mm}$ ID smooth copper pipe including the connector and shroud. A Magnehelic gage with a $0-1 \mathrm{~cm} \mathrm{H}_{2} \mathrm{O}$ range measures the differential pressure from two radius taps. To minimize error, the complete system should be calibrated with a known flow rate source.

\section{Plumbing}

Copper piping $28.6 \mathrm{~mm}\left(1-1 / 8^{\prime \prime}\right)$ OD connects the output from the blower and the generator. A corrigated flexible vacuum cleaner hose with a $35 \mathrm{~mm}$ ID plus a short section of rigid ABS plastic pipe (intended for vacuum cleaner use) with similar size are also connected to direct the test aerosol to a shroud.

\section{Shroud}

The circular plastic shroud is about $20 \mathrm{~cm}$ in diameter and $16 \mathrm{~cm}$ deep. It is large enough to completely cover almost all known commercial smoke detectors. Small diameter holes located at the periphery of the shroud allow the test aerosol to exhaust out while the shroud covers the detector under test.

To avoid direct high velocity aerosol impingment on the test detector from the pipe, a diffuser cap covers the pipe and directs the flow to the side. The flow velocity parallel to the shroud is on the order of 0.5 $\mathrm{m} / \mathrm{min}$. 


\section{APPENDIX B. CHARACTERISTICS OF THE PARTICLE MASS MONITOR}

The mass monitor is based on the high sensitivity of the resonant frequency of a quartz crystal to changes in mass due to deposition of particles on a crystal surface. In practice, the aerosol is drawn into the electrostatic precipitator chamber of the monitor at a flow rate of $1 \mathrm{~L} / \mathrm{min}$ by a vacuum source. The particles in the sample stream are deposited onto the surface of a piezoelectric quartz crystal by a highly efficient electrostatic precipitator. The resonant frequency of the quartz crystal decreases linearly with the total mass of the particle deposited, thereby providing a measure of the mass concentration. The time rate-of-change of the output frequency signal is directly proportional to the total particle mass concentration. 


\section{REFERENCES}

[1] McGuire, J. H. and Ruscoe, B. E., Fire Study No. 9, National Research Council, Canada (1962).

[2] Bukowski, R. W., Waterman, T. E. and Christian, W. J., Detector Sensitivity and Siting Requirements for Dwellings, Nat. Bur. Stand. (U.S.), NBS-GCR 75-51 (1975).

[3] Bright, Richard G., Nat. Bur. Stand. (U.S.) (1977), private communication.

[4] Bright, Richard G., Status Report on Residential Smoke Detectors, NFPA Annual Meeting, Washington, D.C. (May 1977).

[5] Boyd, H., Test of Smoke Detectors, Fire Journal, Vol. 71, p. 83-84, (Jan. 1977).

[6] Cadle, R. R., The Measurement of Airborne Particles, John Wiley \& Son, New York (1976).

[7] Phalen, R. F., Cannon, W. C. and Esparza, D., Comparison of Impaction, Centrifugal Separation and Electron Microscopy for Sizing Cigarette Smoke, Fine Particles - Aerosol Generation, Measurement, Sampling and Analysis, Liu, B.Y., Editor, Academic Press, Inc. (1976).

[8] Mulholland, G. W., Liu, B. Y. H. and Kapadia, A., Accuracy of the Electrical Aerosol Analyzer for Measuring Number and Volume Concentration of Polydisperse Aerosols, to be submitted to J. Colloid and Interface. Sci.

[9] Bukowski, Richard W. and Bright, Richard G., Results of Full-Scale Fire Tests with Photoelectric Smoke Detectors, Nat. Bur. Stand. (U.S.), NBSIR 75-700 (1975).

[10] Smoke Detector, Consumer Report, p. 555 (Oct. 1976).

[11] Standard for Single and Multiple Stations Smoke Detectors, UL 217 , Underwriters' Laboratories, Inc. (Jan. 1976). 
[12] Lee, Thomas G. K. and Mulholland, George, Physical Properties of Smokes Pertinent to Smoke Detector Technology, Nat. Bur. Stand. (U.S.), NBSIR 77-1312 (Nov. 1977).

[13] Liu, B. H. H. and Pui, D. Y. D., On the Performance of the Electrical Aerosol Analyzer, J. Aerosol Sci., Vol. 6, 24 (1975).

[14] Willeke, Klaus, and Liu, B. Y. H., Single Particle Counter, Fine Particles - Aerosol Generation, Measurement, Sampling and Analysis, Liu, B. Y., Editor, Academic Press, 697 (1976).

[15] Newton, G. J., Raabe, O. G. and Mokler, B. V., Cascade Impactor Design and Performance, J. Aerosol Sci., Vol. 8, 337 (1977).

[16] Andersen, A. A., New Sampler for Collection, Sizing and Enumeration of Viable Airborne Particle, J. Bacteriol., Vol. 76, 471-484 (1958).

[17] Bukowski, R. W., Standardized Instrumentation for Smoke Measurements in Large-and Sma11-Scale Testing, NFPA Annual Meeting, Washington, D.C. (May 1977).

[18] Mercer, T. T., Goddard, R. F. and Flores, R. L., Output Characteristic of Several Commercial Nebulizers, Annals of Allergy, Vol. 23 (1965).

[19] Raabe, 0. G., The Generation of Aerosols of Fine Particles, Fine Particles - Aerosol Generation, Measurement, Sampling and Analysis, Liu, B. Y., Editor, Academic Press, Inc. (1976).

[20] Marple, V. A. and Willeke, K., Inertial Impactors: Theory, Design and Use Fine Particles - Aerosol Generation, Measurement, Sampling and Analysis, L1u, Y. Y., Editor, Academic Press, New York (1976). 
Table 1. Alarm Threshold of Typical Smoke Detectors ${ }^{*}$

\begin{tabular}{|c|c|c|c|c|c|c|c|c|c|c|}
\hline Rotameter & Concentration & & & & & ctors & & & & \\
\hline Setting & $\mathrm{mg} / \mathrm{m}^{3}$ & A & $B$ & $\mathrm{C}$ & D & $E$ & $F$ & G & $\mathrm{H}$ & $I$ \\
\hline 110 & 10.5 & 050 & & & & & & & & \\
\hline 105 & 11.8 & - 30 & & & & & & & & \\
\hline 100 & 13.0 & - 21 & 050 & 050 & & & & & & \\
\hline 95 & 14.5 & & - 15 & 050 & & & & & & \\
\hline 90 & 16.0 & $\cdot 18$ & -20 & -50 & 060 & & 050 & & & \\
\hline 85 & 17.5 & & - 11 & & 050 & 050 & 050 & 055 & & 050 \\
\hline 80 & 19.0 & - 30 & & $\bullet 37$ & $\bullet 25$ & $\begin{array}{l}055 \\
\cdot 30\end{array}$ & - 4 & 050 & 050 & \\
\hline 75 & 20.5 & & & & & $\bullet 12$ & & - 16 & & \\
\hline 70 & 22.5 & & & & & - 9 & $\cdot 10$ & $\bullet 13$ & 050 & \\
\hline 65 & 24.0 & & & & & & & & 050 & \\
\hline 60 & .26 .0 & & & $\cdot 25$ & $\bullet 15$ & & & & $\cdot 40$ & 050 \\
\hline 55 & 27.7 & & & & & & & & & 050 \\
\hline 50 & 30.5 & & & & & & & & & - 12 \\
\hline 45 & 32.3 & & & & & & & & & \\
\hline 40 & 35.0 & & & & & & & & & - 16 \\
\hline 35 & 37.7 & & & & & & & & & \\
\hline 30 & 40.5 & & & & & & & & & \\
\hline 25 & 43.5 & & & & & & & & & \\
\hline 20 & 46.5 & & & & & & & & & \\
\hline 10 & 53.0 & & & & & & & & & \\
\hline 0 & 60.0 & & & & & & & & & \\
\hline
\end{tabular}

* Number denotes response time in second

- Failed to alarm

- Alarm 


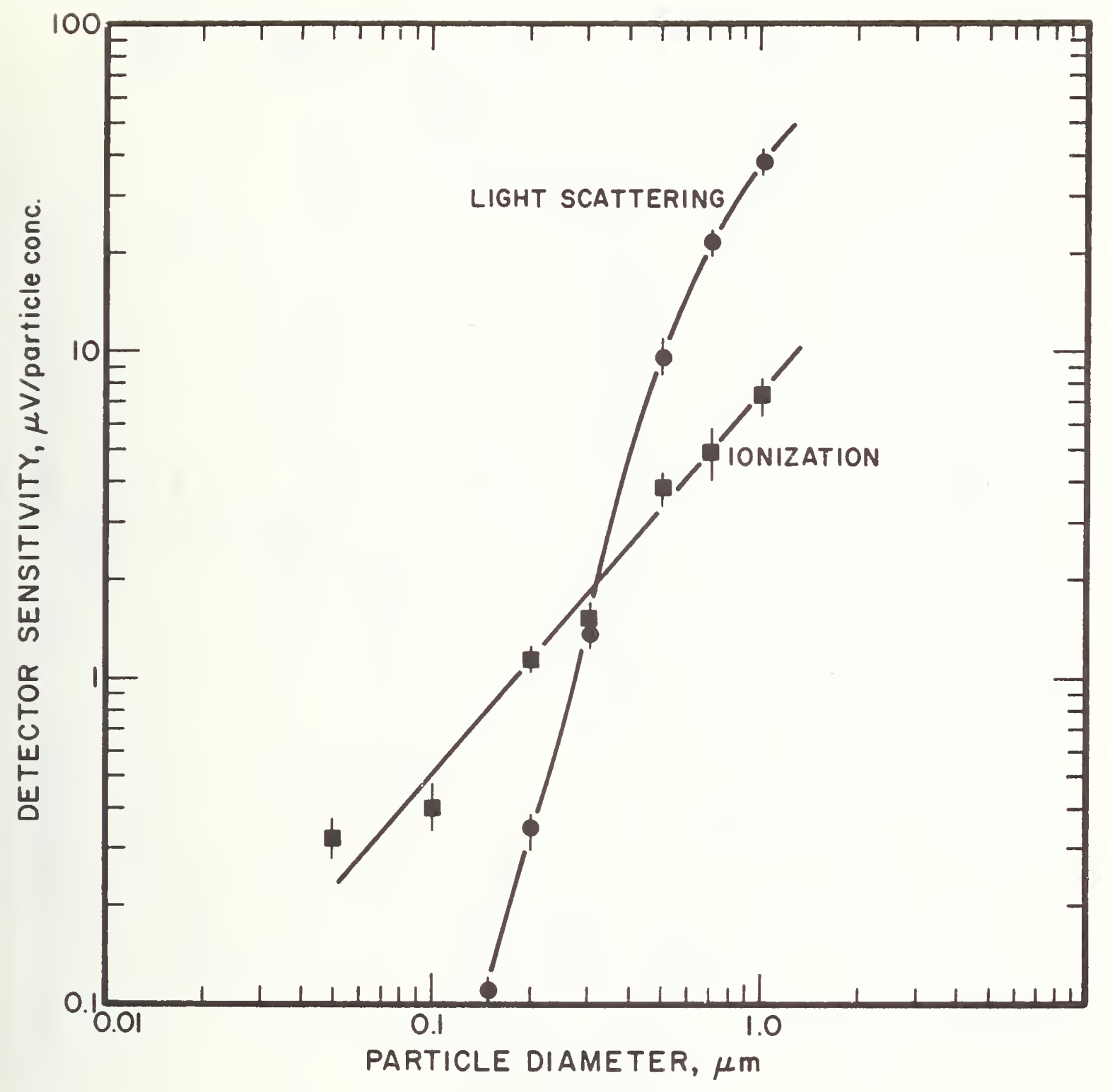

Figure 1. Sensitivity of two types of detectors exposed to monodisperse aerosols [8]. 


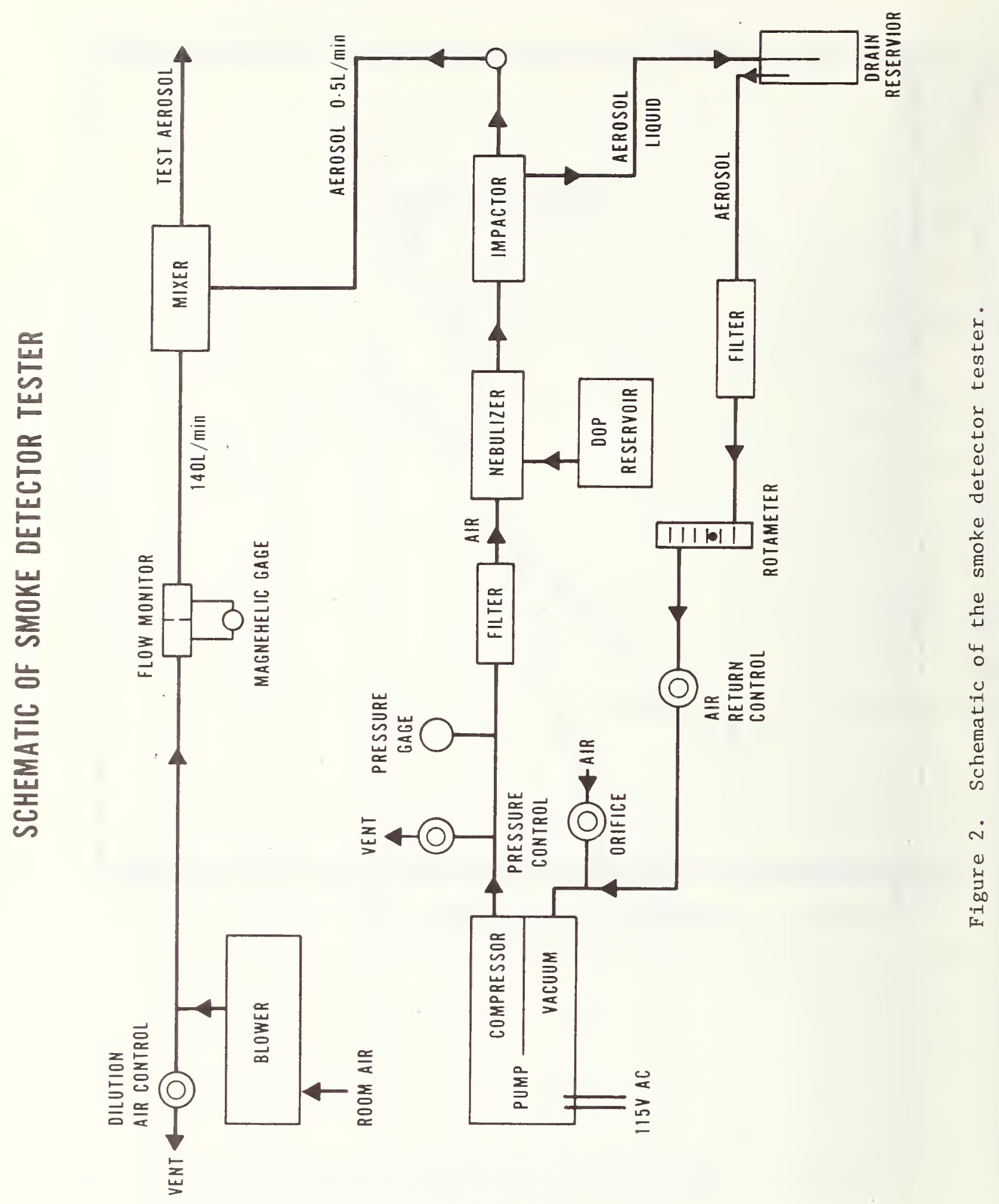




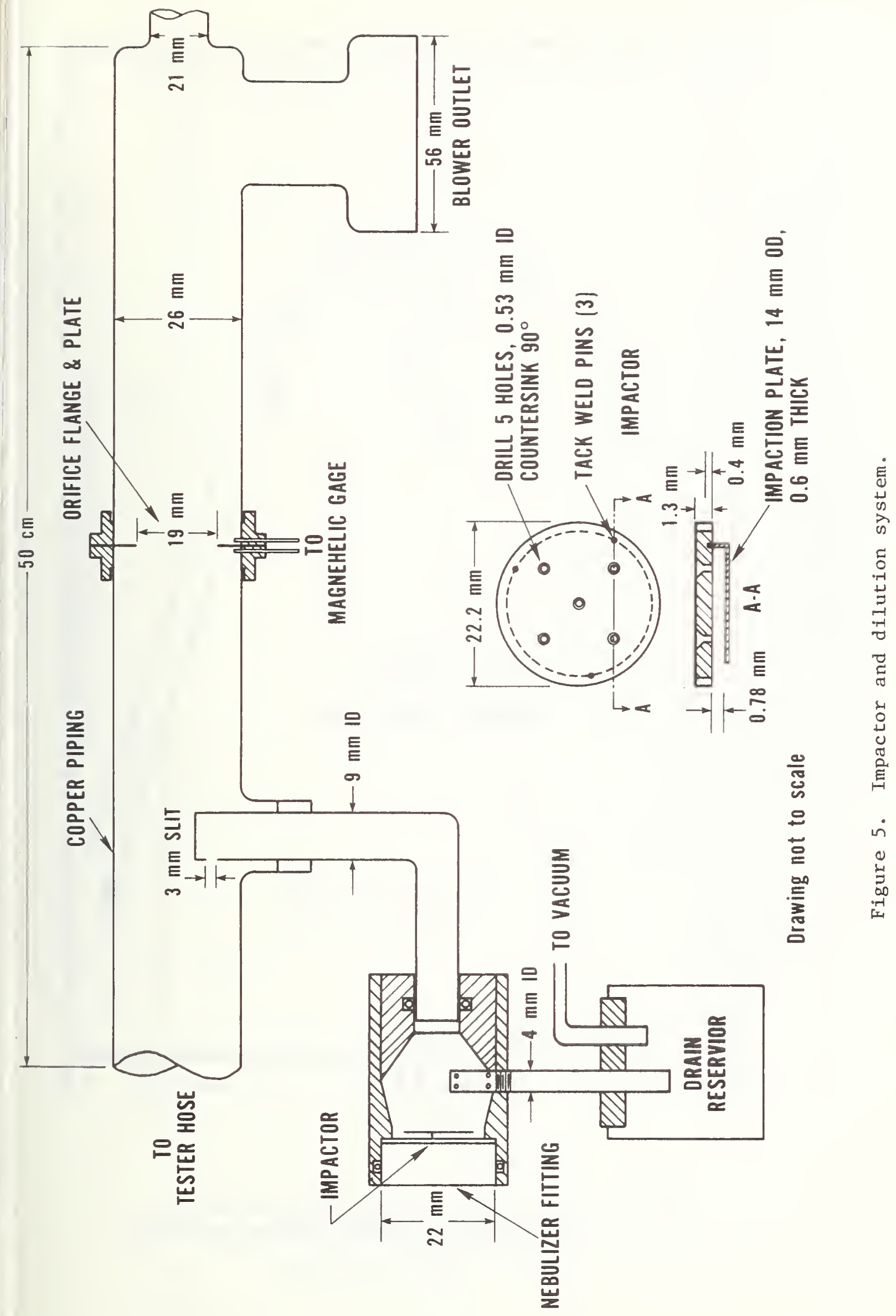




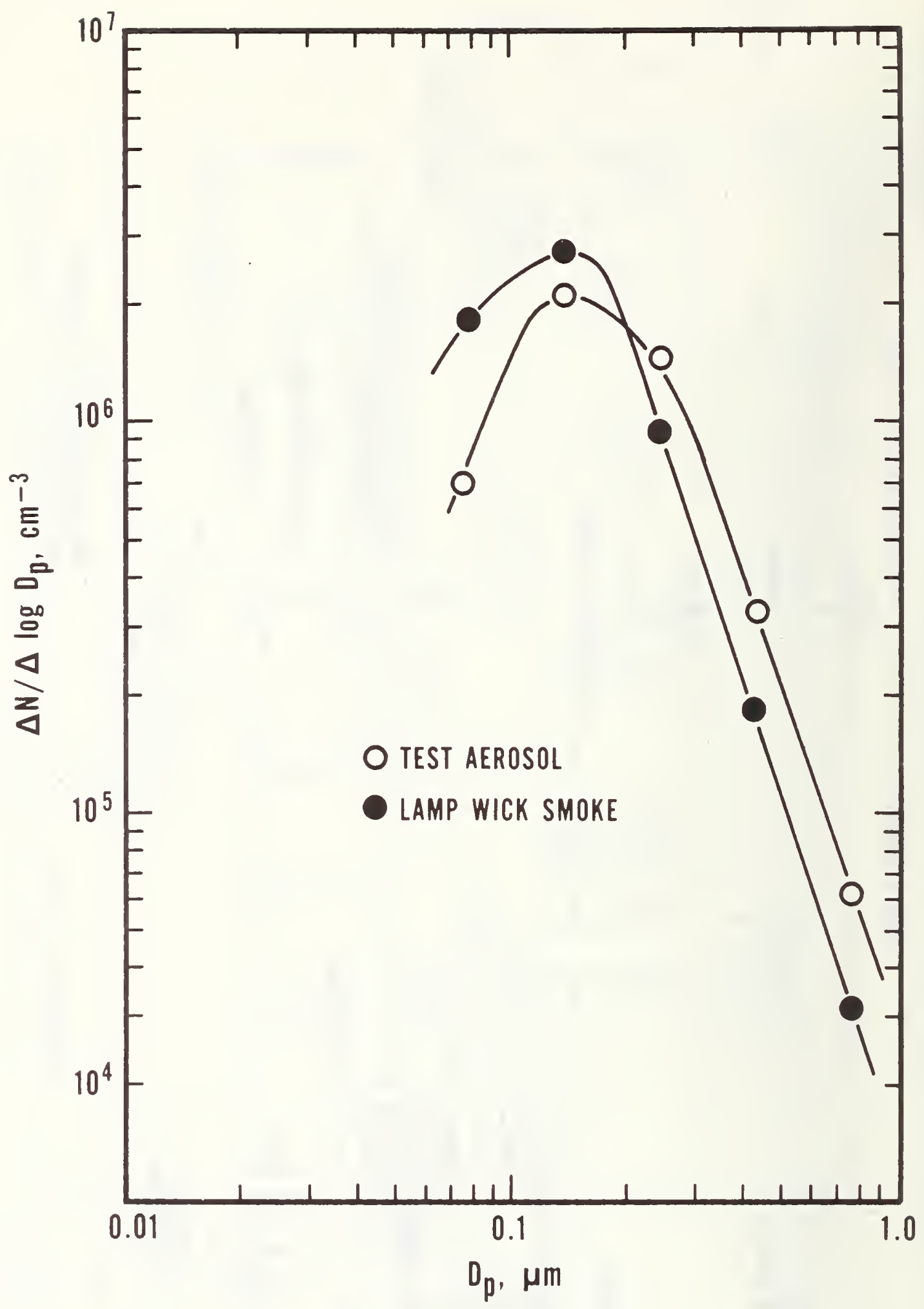

Figure 6. Size distribution of test aerosol and lamp wick smoke as measured by EAA. 


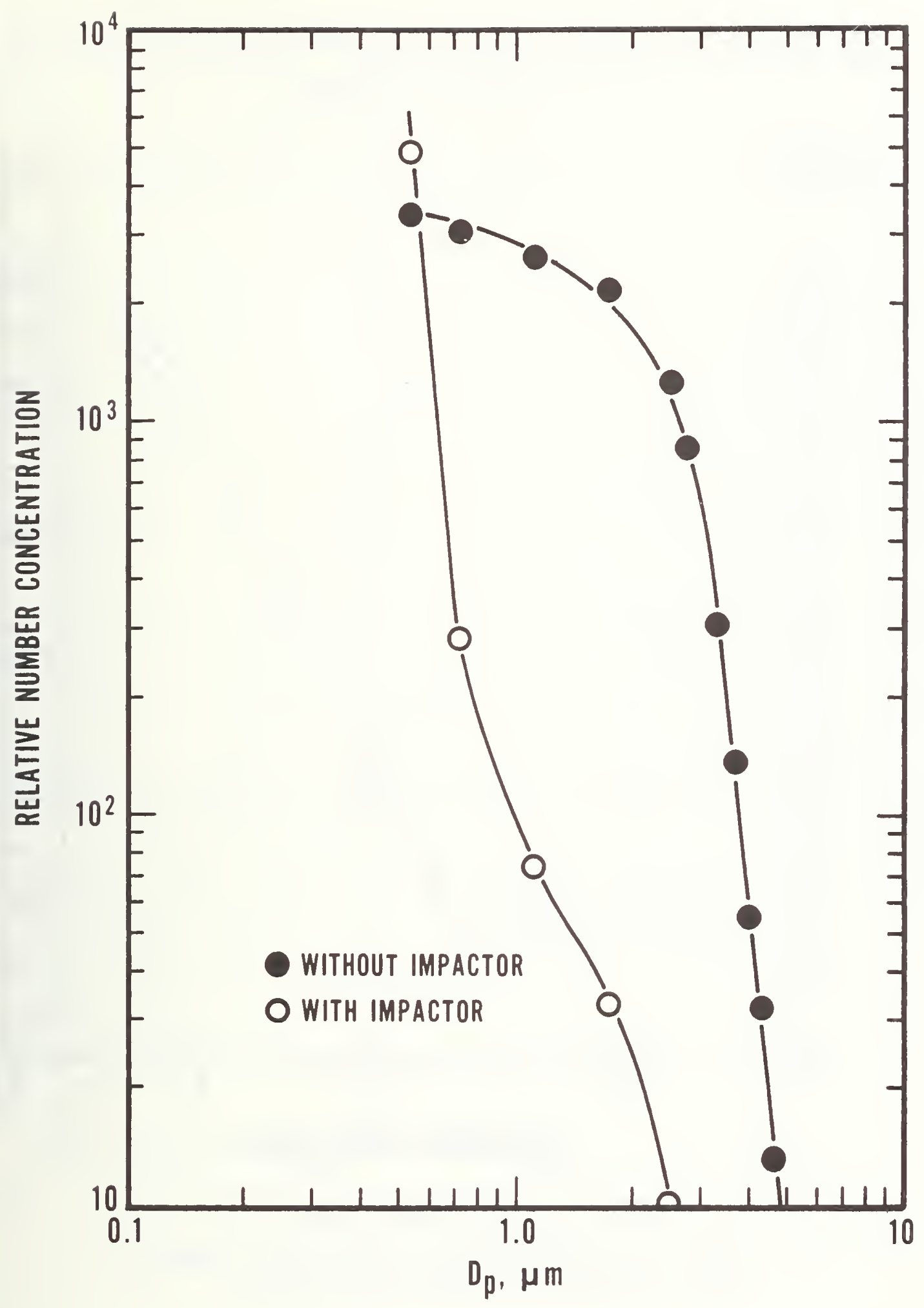

Figure 7. Relative number concentration of test aerosol at selected size ranges as measured by the particle optical counter. 


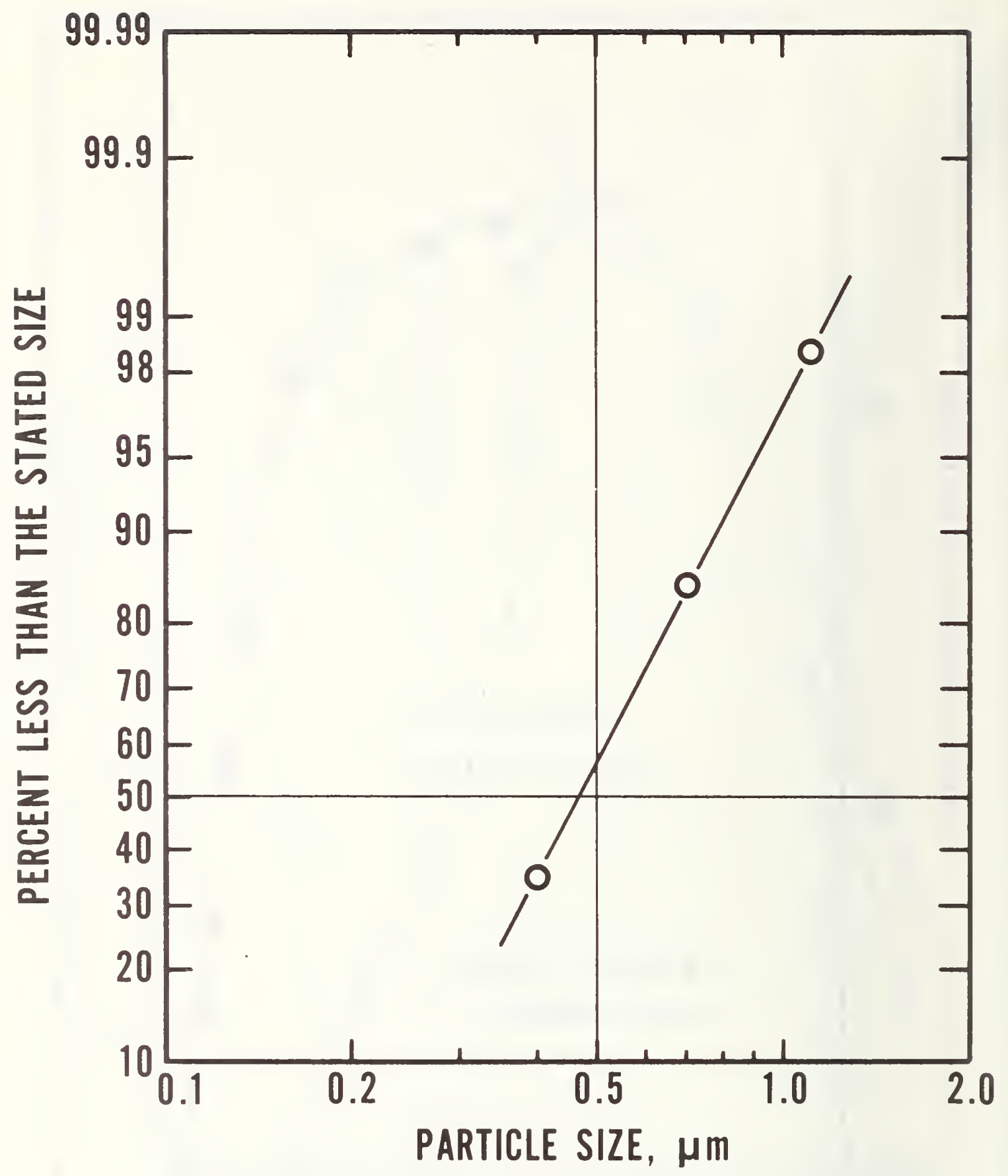

Figure 8. Logarithmic probability plots of the cumulative mass distribution of the test aerosol. 


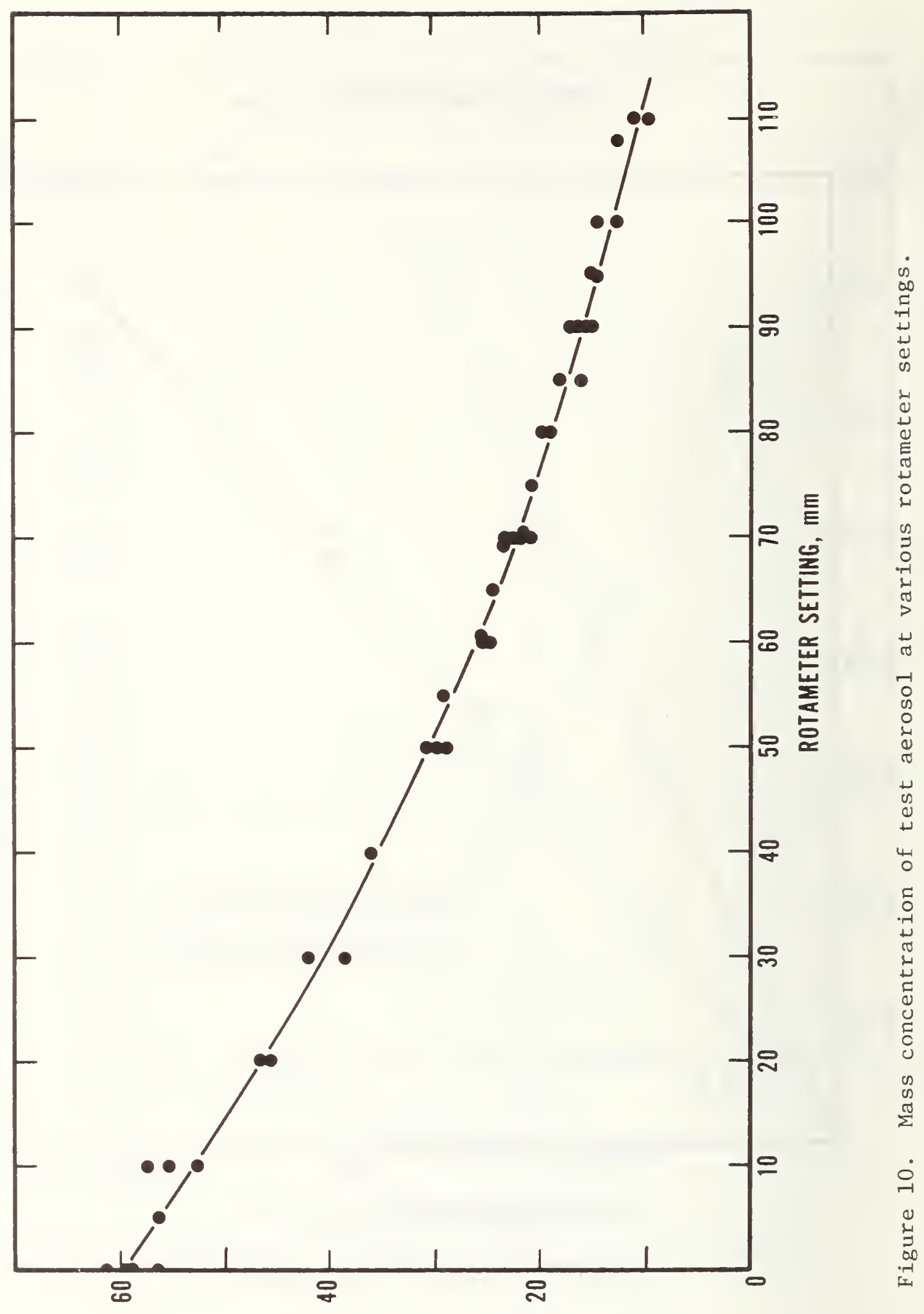

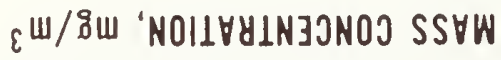


NBS-114A IREV, 7-73)

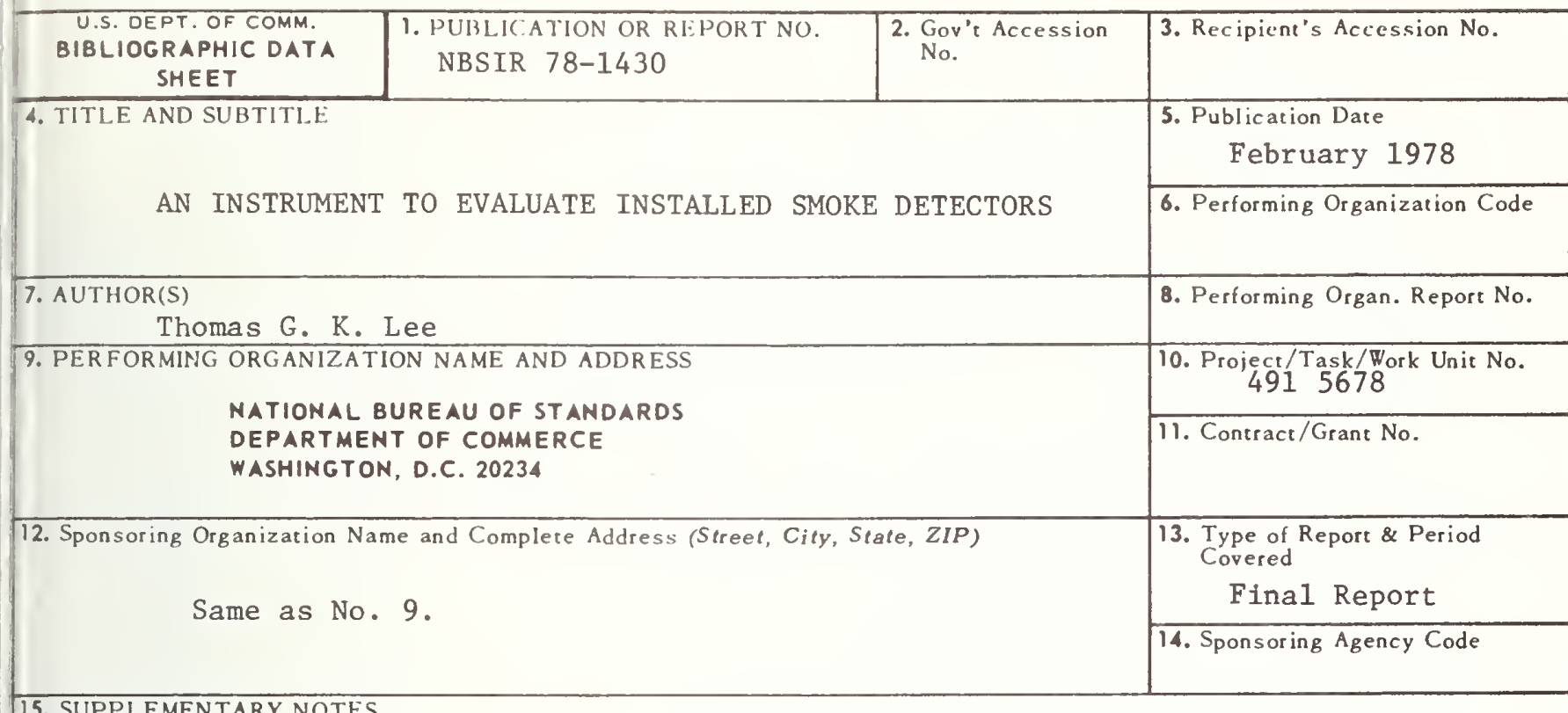

\section{SUPPLEMENTARY NOTES}

16. ABSTRACT (A 200-word or less factual summary of most significant information. If document includes a significant bibliography or literature survey, mention it here.)

An inexpensive portable instrument has been constructed to test the sensitivity response of installed fire smoke detectors. The test stream consists of impactor-selected small particles from aerosol generated by a pneumatic nebulizer and dilution air. The flow rate of the test stream is $140 \mathrm{~L} / \mathrm{min}$ and its aerosol concentration can be varied from 10 to $60 \mathrm{mg} / \mathrm{m}^{3}$, sufficient to cover the sensitive ranges of the nine typical detectors tested. The aerosol mass median particle diameter of $0.46 \mu \mathrm{m}$ and the breadth of the size distribution in terms of geometric standard deviation, is 1.5. The size distribution of the polydisperse aerosol at the output is independent of the aerosol concentration in the range of interest and is comparable to some fire smokes. Aerosol light obscuration as measured by a standardized photometer is linear with respect to the aerosol mass concentration $\left(\mathrm{mg} / \mathrm{m}^{3}\right)$ and has a ratio $2.3 \mathrm{~m}^{2} / \mathrm{g}$ for this aerosol compared to $1.5 \mathrm{~m}^{2} / \mathrm{g}$ for cotton lampwick smoke in the UL 217 chamber.

17. KEY WORDS (six to twelve entries; alphabefical order; capitalize only the first letter of the first key word unless a proper name; separated by semicolons)

Aerosol generators; detector sensitivity; detector testers; light obscuration; particle size distribution; polydisperse aerosol; smoke detector. X Unlimited

— For Official Distribution. Do Not Release to NTIS

Order From Sup. of Doc., U.S. Government Printing Office Washington, D.C. 20402, SD Cat. No. C13

Order From National Technical Information Service (NTIS) Springfield, Virginia 22I5I

\begin{tabular}{|l|c|}
\hline $\begin{array}{l}\text { 19. SECURITY CLASS } \\
\text { (THIS REPURT) }\end{array}$ & 21. NO. OF PAGES \\
UNCL ASSIFIED & 38 \\
\hline $\begin{array}{l}\text { 20. SECURITY CLASS } \\
\text { (THIS PAGE) } \\
\text { UNCLASSIFIED }\end{array}$ & $\begin{array}{c}\text { 22. Price } \\
\$ 4.50\end{array}$ \\
\hline
\end{tabular}


